\title{
Pagamento por serviços ambientais: um instrumento de mitigação dos efeitos de variação climática e uma ferramenta de gestão para crise hídrica na bacia do Alto Descoberto
}

\author{
Ana Paula Silva CAMELO ${ }^{1 *}$, Keila Lima SANCHES ${ }^{2}$ \\ ${ }^{1}$ Programa de Pós-Graduação em Ciências Florestais, Universidade de Brasília, Brasília, DF, Brasil. \\ ${ }^{2}$ Instituto Federal de Brasília, Campus Samambaia, Brasília, DF, Brasil. \\ *E-mail: paulaflorestal@gmail.com
}

Recebido em julho/2018; Aceito em junho/2019.

RESUMO: A escassez de água doce é uma das principais preocupações do século XXI. As últimas projeções do IPCC preveem que para a região do Centro-Oeste deve ocorrer aumento da área agriculturável, diminuição das áreas florestais, aumento de temperatura e alteração da frequência e magnitude de cheias e de períodos de estiagem. Essas alterações afetam profundamente o ciclo hidrológico e por consequência a disponibilidade de água para consumo humano. No verão de 2016/2017 o Distrito Federal registrou a maior crise hídrica de sua história onde o volume do reservatório responsável pelo abastecimento de mais da metade da população ficou abaixo de $10 \%$. Nesse sentido o presente estudo teve como principal objetivo trazer informações atualizadas sobre Pagamento por Serviços Ambientais, como um importante instrumento mitigador de mudanças climáticas, redutor de processos de alteração do uso do solo, sugerindo-o como instrumento para promover melhorias no abastecimento de água da Bacia do Descoberto.

Palavras-chave: mudanças climáticas; gestão hídrica; serviços ecossistêmicos.

\section{Payment for environmental services: an instrument of mitigation of the effects of climate change and a management tool for hydrical crisis in the Alto Descoberto watershed}

\begin{abstract}
Freshwater shortages are one of the main concerns of the 21 st century. The latest projections by the Intergovernmental Panel on Climate Change (IPCC) foresee that for the brazilian midwest, there should be an increase in the area planted to agriculture, a decrease in forest areas, an increase in temperature and a change in the frequency and magnitude of floods and droughts. These changes profoundly affect the hydrological cycle and consequently the availability of water for human consumption. In the summer of 2016/2017, the Federal District had the greatest water crisis in its history, where the volume of the reservoir responsible for supplying more than half the population was below $10 \%$. In this sense, the main objective of the present study was to provide updated information on payment for environmental services as an important instrument to mitigate climate change, reducing soil use change processes, and suggesting it as an instrument to promote improvements in water supply in the Descoberto watershed.
\end{abstract}

Keywords: climate change; water management; ecosystem services.

\section{INTRODUÇÃO}

Desde a Convenção-Quadro das Nações Unidas sobre Mudanças Climáticas em 1992, há uma preocupação quanto à escassez de água doce ser um dos principais resultados dos processos das mudanças climáticas. Todavia, além da questão climática, apontam-se outros responsáveis para o problema da falta de água, como as políticas inadequadas de gestão dos recursos hídricos e a falta de educação ambiental dos cidadãos (MARENGO et al., 2015).

Em relação à disponibilidade de recursos hídricos, as projeções do IPCC (2013) levam em consideração a evolução das variáveis naturais, mas também a evolução das condições socioeconômicas. Ainda segundo o relatório do IPCC, para a região do Centro Oeste deve ocorrer aumento da área agriculturável, diminuição das áreas florestais, aumento da temperatura e alteração da frequência e magnitude de cheias e de períodos de estiagem.

As alterações no ciclo hidrológico de uma região são relacionadas a diversos fatores, tais como a própria variabilidade do clima, mudanças causadas por fenômenos naturais ou antrópicos, mas também com fatores não climáticos, como alterações na cobertura e uso do solo (SANDERSON et al., 2002). Além de alterações na recarga de aquíferos, mudança no regime de vazões causada pela construção de barragens e alteração no uso da água, todas amplamente dependentes do sistema humano, cujo comportamento está relacionado ao desenvolvimento econômico, crescimento populacional e à adoção de soluções de gestão dos recursos hídricos.

Neste contexto e tomando como base o ano hidrológico 2016/2017 o Distrito Federal registrou a maior crise hídrica de sua história. Em geral, pode-se dizer que a crise hídrica é gerada por uma conjunção de fatores que incluem a falta de gerenciamento dos recursos hídricos e a escassez de chuva. Em 2017 foi desenvolvido um Plano Integrado de Enfrentamento à Crise Hídrica (GDF,2017), onde foram apontadas como estratégias diversas atividades integradas que previam melhorar a relação da população com o uso dos recursos hídricos, mas não aponta o uso de instrumentos como o Pagamento por Serviços Ambientais. 
Além disso, conforme observado por Sone et al. (2019) no Brasil há uma maior disposição, por parte dos gestores, para tomada de decisões de medidas imediatistas como solução dos problemas relacionados a escassez hídrica em detrimento de ações preventivas. Dessa forma, medidas como racionamento de distribuição de água, aumento das tarifas e construção de novas captações são mais utilizadas do que a implementação política de gerenciamento à longo prazo.

Ainda nesse sentido, para Rickert et al. (2019) nos últimos anos, há a necessidade de ampliação da abordagem do planejamento hídrico para um planejamento hídrico resiliente as mudanças climáticas. Essa mudança é imperativa devido ao conhecimento da relação dos impactos do clima na disponibilidade de água potável. Dessa forma, os planos de gerenciamento atuais necessitam abarcar medidas de adaptação às mudanças climáticas previstas.

A Bacia do Rio Descoberto, onde está localizado o reservatório do Rio Descoberto, compreende uma área de 825 $\mathrm{km}^{2}$, correspondendo a $14 \%$ do território do Distrito Federal. No ano de 2006 o uso e cobertura do solo na bacia do Alto Descoberto era composto principalmente por áreas urbanas ou núcleos rurais e áreas de cultura anual (SIEG, 2017).

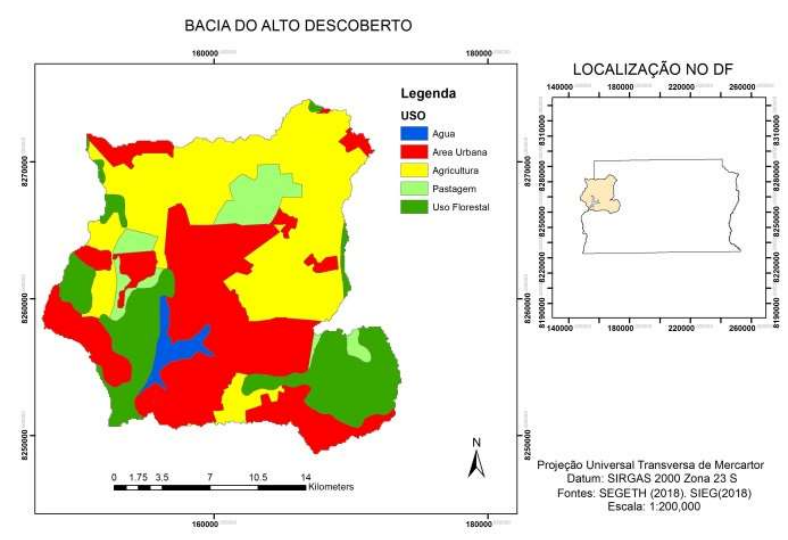

Figura 1. Localização da bacia do Descoberto no Distrito Federal. Figure 1. Location of the Descoberto basin in the Distrito Federal.

A média anual das precipitações na Bacia do Descoberto oscila entre 1200 e 1750 milímetros (BUENO, 2016). E seu reservatório abastece cerca de $60 \%$ da população do Distrito Federal e entorno (FONSECA, 2001). Além disso, cabe ressaltar alguns aspectos socioeconômicos da bacia na qual sua população, no geral, apresenta uma baixa escolaridade e baixa renda per capita (CODEPLAN, 2017).

A partir do ano de 2016 a Agência Reguladora de Águas, Energia e Saneamento Básico do Distrito Federal (ADASA) informou por meio de boletins o baixo nível do principal reservatório de abastecimento do Distrito Federal. Os boletins de informação da ADASA informam que nos anos de 2016 e 2017 as chuvas do DF estão abaixo do previsto sendo esse o principal motivo da crise hídrica. No entanto estudos como, Nunes et al. (2014) e Bueno (2016) alertam para a alta taxa de modificação do uso do solo da bacia que prejudica o fornecimento dos serviços ambientais e principalmente dos serviços ambientais hidrológicos.

Em bacias onde houve alterações decorrentes do processo de uso e ocupação, como desmatamento, alteração topográfica, compactação e impermeabilização do solo há redução da capacidade de infiltração do solo, aumentando significativamente a geração de escoamento superficial (FLETCHER et al., 2013). Isso implica dizer que a cada evento chuvoso menos água fica retida na bacia, ou seja, há menos reserva de água para períodos de estiagem. Por outro lado, em bacias florestadas o fluxo é mais estável e sustentável do que em outros casos (BALBINOT et al., 2009).

A evapotranspiração, a taxa de infiltração, o escoamento direto, a quantidade de água disponível, a uniformidade das vazões e a qualidade da água são serviços hidrológicos que podem ser afetados pela alteração do uso do solo (BALBINOT et al., 2009; PORRAS et al., 2008). Os serviços ambientais e sua valoração serão a base para uma governabilidade adequada dos recursos hídricos.

Considerando os aspectos citados da Bacia do Rio Descoberto, Azevedo; Barbosa (2011) alertam sobre a urgência de disciplinar o uso do solo, o tratamento de esgoto dos núcleos urbanos, monitorar e controlar o uso de agrotóxicos e racionalizar o processo de irrigação, com vista a se garantir a qualidade e quantidade de água para o abastecimento agrícola e urbano.

O plano integrado de enfretamento da crise hídrica do DF aponta como uma das principais dificuldades a preservação e manutenção de áreas de recargas hídricas que são as áreas mais importantes para regular a retenção de água em uma bacia. O termo recarga representa a quantidade de água, por unidade de área, que penetra no subsolo até atingir o lençol freático contribuindo para aumentar a reserva subterrânea permanente ou temporária de aquífero, e, no caso da reserva temporária, é considerada como reserva reguladora ou renovável, que pode ser considerada como reserva explotável (VASCONCELOS, 2005). A água proveniente da precipitação pluvial é o principal mecanismo de entrada de água no sistema aquífero e o volume de água destinado à recarga é dependente de fatores como interceptação (cobertura do solo), evapotranspiração e escoamento superficial (JYRKAMA et al., 2007).

Assim, verificado a importância da aplicação de boas práticas de manejo para o aumento da infiltração e, portanto, da regulação de vazões em bacias hidrográficas, esse estudo tem como objetivo propor um sistema de pagamento por serviços ambientais para a Bacia do Descoberto visando a diminuição da alteração do uso do solo e prover serviços ambientais referentes a melhoria da vazão de abastecimento de água.

\section{DESENVOLVIMENTO}

2.1. O que são Serviços Ambientais e Pagamentos por Serviços Ambientais?

Os ecossistemas naturais disponibilizam uma série de benefícios como regulação climática, regulação de fluxos hidrológicos, armazenamento e sequestro de carbono, conservação da biodiversidade, conservação e regeneração dos solos, ciclagem de nutrientes, controle de doenças, controle de poluentes, belezas cênicas, entre outros (WUNDER, 2008). Esses benefícios são denominados serviços ambientais ou serviços ecossistêmicos.

Os serviços hidrológicos são bastante diversificados, porém Brauman et al. (2007) propôs uma organização desses serviços em cinco grandes categorias (1) melhoria do abastecimento de água para usos consuntivos; (2) melhoria da vazão de abastecimento de água; (3) mitigação danos causados pela água; (4) fornecimento de água relacionados 
com os serviços culturais; e (5) água associada serviços de suporte.

Os serviços ambientais são externalidades, uma vez que proporcionam benefícios que não são pagos e, portanto, não são internalizados nas decisões econômicas (KOSOY; CORBERA, 2010). De acordo com Wünscher et al. (2008) os pagamentos por serviços ambientais (PSA) tem se tornado um crescente instrumento de mercado capaz de traduzir as externalidades positivas, ou seja, os serviços ambientais não mercantis, em incentivos financeiros para que os proprietários preservem os ecossistemas que provêm os serviços. O conceito de pagamentos por serviços ambientais foi criado como um mecanismo para melhorar a eficiência da gestão de recursos naturais.

Dos muitos serviços dos ecossistemas que as bacias hidrográficas fornecem, serviços hidrológicos constituem alguns dos mais economicamente e socialmente valioso (PORRAS et al, 2008). Ecossistemas e os serviços por eles gerados são complexos e pode ser apropriado pagar até mesmo para serviços ainda com definições defasadas (FARLEY; COSTANZA, 2010). Sabe-se que há uma considerável incerteza sobre os serviços ambientais hidrológicos de regulação prestados pelas florestas e outros usos da terra, entretanto há sistemas dispostos a pagar por estes serviços (PORRAS et al., 2008). Além disso, o Princípio 15 da Declaração Rio/92 é a expressão legislativa mais importante que institucionaliza o princípio da precaução como marco do Direito Ambiental Internacional. A assertiva de que, frente à ameaça de danos graves ou irreversíveis e ausência de certeza científica absoluta, a decisão deverá ser em favor do meio ambiente, é o que consagra o princípio da precaução (HUPFFER et al., 2011).

Segundo Kosoy; Corbera (2010) os pagamentos por serviços ambientais (PSA) recompensam de maneira econômica gestores de recursos naturais que prestam serviços ambientais sendo caracterizado pela (1) existência de uma função ecológica comerciável, (2) estabelecimento de uma unidade padrão de troca, (3) e da oferta, demanda e intermediação fluxos entre aqueles que vendem e compram serviços dos ecossistemas.

Wunder (2005) define pagamentos por serviços ambientais (PSA) como (1) uma transação voluntária, (2) com um serviço ecológico bem definido, (3) tendo pelo menos um comprador, (4) com pelo menos um ofertante e (5) se e somente se o ofertante garantir o provimento do serviço ambiental. Sendo essa última premissa um condicionante do pagamento.

Para Van Hecken; Bastiaensen (2010) a base conceitual para o PSE conforme estipulado por Wunder (2005) está inserida na economia ambiental neoclássica visto que o PSA parte do princípio que a degradação ambiental é atribuída à falha crônica dos mercados em internalizar externalidades ambientais, além da indução ao free-riding, dada a natureza de bem público que os serviços ecossistêmicos possuem. Portanto, a filosofia do PSA defende a internalização de externalidades ambientais através da criação de mercados e "quase-mercados".

Por meio da criação desses mercados presume-se que atores privados ponham em prática o teorema de Coase, ou seja, a solução para as externalidades negativas se dará através de negociações privadas entre as partes afetadas. Ou seja, beneficiários de práticas ambientais sólidas que forneçam e / ou mantenham os serviços ecossistêmicos valiosos pagam aos administradores de terras a adoção de práticas de uso da terra que supostamente fornecem esse serviço demandado e contratado (SCHOMERS; MATZDORF, 2013).

No entanto é importante ressaltar que as soluções para “internalização de externalidades" propostas por Coase são uma contraposição ao trabalho de Pigou. A solução pigouvina propunha a intervenção do Estado para a correção das externalidades negativas por meio de cobranças, estabelecidas com base na diferença entre o custo marginal privado e o custo marginal social.

No entanto, observa-se que grande parte dos PSA não tem como base o modelo Coaseano visto que na maioria deles há a participação direta do Estado. Nesses modelos o setor público atua como custodiante em nome dos usuários de água, que não necessariamente pagam diretamente pelo serviço ambiental (BÖSCH et al., 2019). Todavia Farley; Costanza (2010) ressaltam que os PSA financiados pelo governo são particularmente comuns quando o serviço ambiental tem impacto global e/ou possui caráter de bem público.

A concepção de 'bem público' refere-se a um bem sob o controle das estruturas de Estado, podendo ser provido através de uma organização pública ou privada (FLORES; MISOCZKY, 2015). No Direito brasileiro, a Política Nacional de Recursos Hídricos define em seu artigo $1^{\circ}$ que a água é um bem de domínio público (BRASIL, 1997).

Para Muradian et al., 2010 as experiências com os pagamentos diretos entre provedor e recebedor privados, isto é, pagamentos diretamente financiados pelos beneficiários, tal como nos pressupostos do mercado coaseaniano, são raros. Grande parte dos programas são baseados em financiamentos públicos ou privados através de um orçamento previamente estabelecido (OUVERNEY et al., 2017).

Dada as divergências entre as bases econômicas dos diversos programas de pagamento por serviços ambientais Wunder (2015) definiu que as diversas adaptações ao conceito original representam adaptações as diversidade e complexidade dos sistemas o que não invalida o PES.

\subsection{Pagamentos por Serviços Ambientais arcabouço jurídico Nacional e Distrital.}

A Lei Federal 12.187/2009 menciona o pagamento por serviços ambientais ao prever a utilização de instrumentos financeiros e econômicos para promover ações de mitigação e adaptação à mudança do clima, que ainda não foram regulamentados (BRASIL, 2009b). Por sua vez a Lei Federal 12.114/2009 cria o Fundo Nacional sobre Mudança do Clima (FNMC) (Brasil, 2009a). Entre as atividades financiadas pelos recursos FNMC estão os PSA às comunidades e aos indivíduos cujas atividades comprovadamente contribuam para a estocagem de carbono, atrelada a outros serviços ambientais.

Mais recentemente, a Lei Federal n ${ }^{\circ} 12.651$ de 2012 autoriza o Poder Executivo Federal a instituir programa de apoio e incentivo à conservação do meio ambiente, bem como para adoção de tecnologias e boas práticas que conciliem a produtividade agropecuária e florestal, com redução dos impactos ambientais como forma de promoção do desenvolvimento ecologicamente sustentável, observados 
sempre os critérios de progressividade, abrangendo entre as linhas de ação a conservação das águas e dos serviços hídricos (BRASIL, 2012).

No Distrito Federal, há a Lei $\mathrm{N}^{0} 5.955$, de 02 de agosto de 2017 que institui a Política Distrital de Pagamentos por Serviços Ambientais e o Programa Distrital de Pagamento por Serviços Ambientais (DISTRITO FEDERAL, 2017). A referida Lei define que os pagamentos por serviços ambientais baseiam-se na valoração econômica e na geração de renda pela manutenção do serviço ambiental e envolvem uma transação voluntária, na qual um serviço ambiental é comprado por, pelo menos, um comprador de, pelo menos, um produtor, sob a condição de que este garanta sua provisão. Entende-se, portanto, que uma proposta de pagamento por serviços ambientais no Distrito Federal deve ter suas bases econômicas bem estabelecidas.

Dentre os objetivos da Política Distrital de Pagamentos por Serviços Ambientais destacam-se a criação programas de Pagamentos por Serviços Ambientais - PSA e o estimulo a criação de novas tecnologias para melhorar a qualidade e a quantidade de água, proteger a biodiversidade e aumentar a eficiência no uso do solo. Além disso, a Lei Distrital ainda cria o Programa Distrital de Pagamentos por Serviços Ambientais - PDPSA com o subprograma Recursos Hídricos que visa a purificação da água, regulação de vazão e redução do assoreamento, atendidas as seguintes prioridades: a) proteger as áreas sujeitas a restrições de uso com vistas à proteção dos recursos hídricos; b) aumentar a purificação da água, a regulação de vazão e a redução da sedimentação; c) incentivar os proprietários rurais a preservarem e recuperarem a vegetação natural no entorno dos cursos d'água; d) atuar nas bacias hidrográficas onde estejam implementados os instrumentos de gestão previstos na Política de Recursos Hídricos do Distrito Federal; e) atuar nas propriedades rurais localizadas a montante dos reservatórios de abastecimento público; f) recuperar os cursos d'água que apresentam acelerado processo de assoreamento e erosão de suas margens; e g) repassar os recursos financeiros arrecadados pelos usos da água para a própria bacia hidrográfica.

Observando as prioridades necessárias para a inclusão de uma bacia no subprograma de Recursos Hídricos da Lei Distrital Lei No 5.955/2017 a bacia do Alto Descoberto estaria apta a ser beneficiada uma vez que atende a todas as prioridades descritas na lei.

\subsection{Estrutura do Programa.}

Conforme preconizado pelo princípio dos pagamentos por serviços ambientais o programa deverá ser de forma voluntária, flexível, de implantação descentralizada e com o objetivo de aumentar a infiltração e retenção de água no solo melhorando o provimento e a regularização das vazões dos córregos que alimentam o reservatório da Bacia do Rio Descoberto. A premissa norteadora é de que a melhoria ambiental obtida pela mudança do uso e cobertura do solo principalmente nas zonas de recarga da bacia é fundamental para regularizar a vazão dos rios responsáveis por alimentar o reservatório de água para o uso consultivo. Na figura 2 está o fluxograma da arquitetura do programa.

Portanto, o primeiro passo necessário é calcular a quantidade de água que será infiltrada e ficará retina no interior da bacia durante o ciclo hidrológico, ou seja, quantificar o serviço ambiental. Para isso é fundamental a utilização de modelos de previsão do tipo chuva-vazão que consiga incorporar aspectos do uso do solo.

Assim como Campanhão;Ranieri (2019) sugere-se que a quantificação do serviço ambiental de regulação de vazão seja realizada pelo modelo Soil and Water Assessment Tool (SWAT), desenvolvido pelo Departamento de Agricultura dos Estados Unidos (USDA) em parceria com a Universidade Texas A\&M (NEITSCH et al. 2005) e mundialmente utilizado como ferramenta de modelagem interdisciplinar robusta em bacias hidrográficas.

Para quantificar a melhoria dos serviços ambientais propõe-se a realização de estudos de cenários da bacia. O desenvolvimento de cenários procura construir diferentes alternativas de futuros e suas interligações e apresenta-se mais consistente que a de previsões e é defendida por importantes autores de estratégia (BOAVENTURA; FISHMANN, 2007).

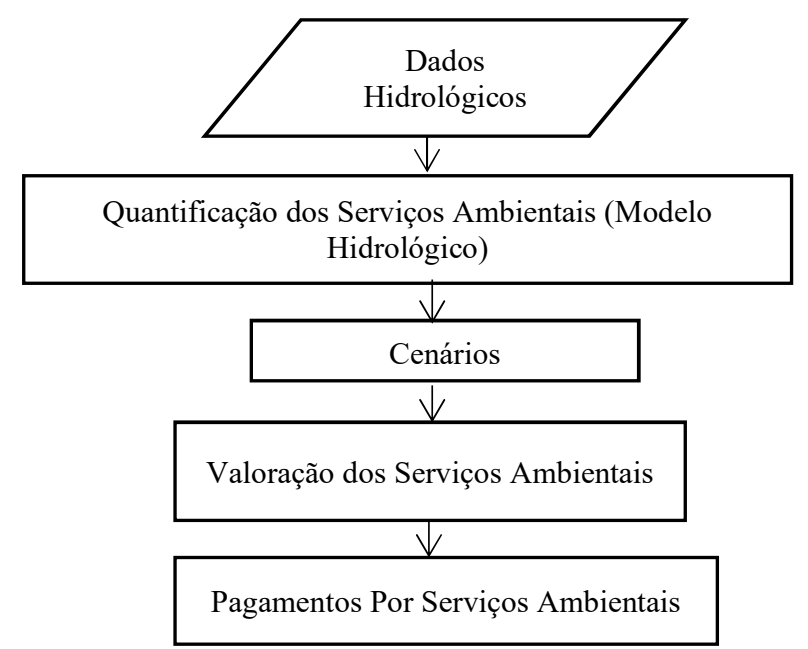

Figura 2. Estrutura do programa de pagamentos por serviços ambientais.

Figure 2. Structure layout of the payment program for environmental services.

Devido às prerrogativas da PDPSA-DF sugere-se a modelagem de diversos cenários onde será avaliada a mudança do atual uso do solo para usos mais sustentáveis e a quantidade de água infiltrada na bacia e posteriormente convertida em vazão. De acordo com Ferreira et al. (2019) a prática de recomposição florestal é que gera maior aumento da disponibilidade de água, porém práticas agrícolas sustentáveis são necessárias para complementar a gestão da água.

Portanto, avaliando a vocação da bacia podem ser modelados usos como recuperação de áreas, recuperação de APP usa de Sistemas Agroflorestais e métodos conservacionistas como plantio direto e terraceamento.

De acordo com Gjorup et al. (2016) os principais aspectos para seleção de áreas prioritárias em programas de pagamento por serviços ambientais hídricos são localização na bacia hidrográfica (montante ou jusante), presença e/ou estado de conservação de APP, localização em áreas de recarga, presença de cobertura vegetal, proximidade com Unidade de Conservação (UC), limiar de declividade.

Propõe-se que a valoração dos serviços ambientais seja realizada o método do custo de reposição (MCR) e os pagamentos por serviços ambientais pagos aos produtores participantes baseados no excedente do consumidor. 


\subsection{Valoração dos Serviços Ambientais}

De acordo com Pearce (1993), o método Custo de Reposição (MCR), é uma forma de valoração indireta, apresenta uma das idéias intuitivas mais básicas quando se pensa em prejuízo: a reparação por um dano provocado. Pearce (1993) afirma que o MCR é frequentemente utilizado como uma medida do dano causado. Essa abordagem é correta nas situações em que é possível argumentar que a reparação do dano gerará benefícios, quaisquer que sejam estes.

Portanto, o MCR considera o custo da reposição de um ativo danificado ou perdido e usa esse custo como proxy parcial ou medida de seu valor, ou seja, reflete apenas uma parte do valor econômico total (JACKSON et al., 2014). Notaro; Paletto (2012) alertam que o MCR é apropriado para estimar o valor econômico de um único serviço ecossistêmico ou um número limitado de serviços.

A metodologia já foi utilizada por Alípaz (2010) para valorar os serviços ambientais redutores de sedimentação na bacia hidrográfica do Ribeirão Pipiripau-DF. Na metodologia utilizada, o custo de reposição (CR) foi calculado como sendo o custo de revegetação da bacia admitindo um ano como o período necessário para o plantio de mudas nativas nas áreas selecionadas.

\subsection{Pagamento dos Serviços Ambientais: O Princípio do} Excedente do Consumidor

O princípio do excedente do consumidor, desenvolvido por Alfred Marshall, é frequentemente usado como um indicador de eficiência de política econômica na economia do bem-estar social. O excedente do consumidor é utilizado pelos economistas para representar o benefício líquido auferido pelo indivíduo quando do consumo de determinado produto, permitindo avaliações em termos de variações de bem-estar. Essa ideia é explorada na curva de demanda para um produto que é perfeitamente divisível. Isso permite construir uma curva de demanda contínua e a aplicação da análise marginalista.

Para Motta (1997), há duas formas de valoração do excedente do consumidor para recursos ambientais a primeira seria gerada pela variação no preço transacionado num mercado, devido à degradação ou à exaustão de recursos. A segunda forma de valoração do excedente do consumidor se refere aos bens e serviços públicos de consumo coletivo e simultâneo, não exclusivo ou não rival.

Alguns cenários de gestão que influenciam o excedente do consumidor (EC). Para este estudo é admitido que ao implementar práticas de manejo conservacionistas haverá um aumento da oferta de água (YANG et al., 2019). Portanto, ao aumentar a oferta de água, deslocamento de $\mathrm{O}_{0}$ para $\mathrm{O}_{1}$, há um aumento do excedente do consumidor ( $\triangle \mathrm{EC})$, representado pela área do trapézio $\mathrm{ABP}_{1} \mathrm{P}_{0}$, sendo $\mathrm{A}$ e $\mathrm{B}$ os pontos de equilíbrio nas ofertas $\mathrm{O}_{0}$ e $\mathrm{O}_{1}$, respectivamente (Figura 3).

Admite-se que o aumento da oferta água será em função do aumento da infiltração que, que por sua vez irá regular a vazão do córrego (HONDA; DURIGAN, 2017). Essa regulação da vazão, principalmente na época da estiagem permitirá um aumento da quantidade de água captada.

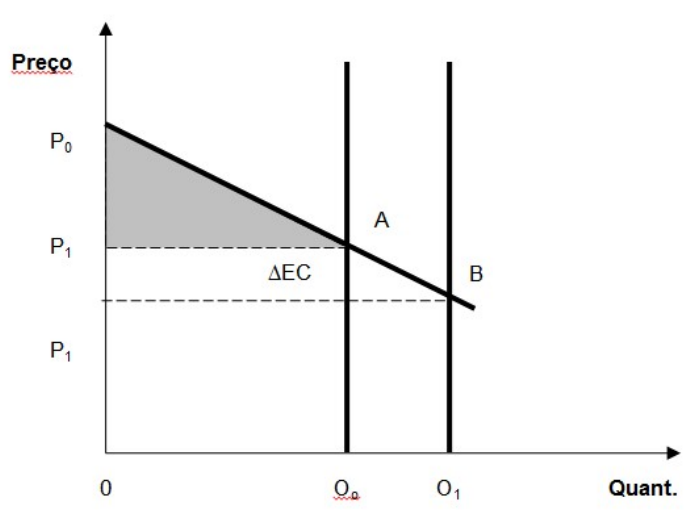

Figura 3. Variação do excedente do consumidor em função da variação da oferta de água.

Figure 3. Variation of consumer surplus due to variation in water supply.

A estimativa do valor do investimento em reais por hectare a ser feito na bacia, admitindo que a companhia de saneamento repasse a sociedade $o$ valor integral dos benefícios gerados pela adoção de práticas conservacionistas na bacia pode ser obtido por meio da seguinte Equação 1:

$$
P S A=\frac{\Delta E C}{A}
$$

em que: PSA é o pagamento por serviços ambientais em $\mathrm{R} \$ /$ ha, EC é o valor do excedente do consumidor gerado pelo aumento da oferta de água em reais e A é a área agriculturável da bacia em hectares.

Ouverney et al., 2017 ressalta o receio dos proprietários rurais em aderir a esses programas devido a sua finitude e principalmente em relação ao custo de oportunidade de se abrir mão de atividades atuais (geradoras de renda) em prol das atividades propostas no programa.

No entanto, no modelo aqui apresentado, os usuários finais de água seriam os responsáveis pela manutenção dos pagamentos por serviços ambientais. De acordo com Jardim; Bursztyn (2015) a parceria consolidada, com diversos setores da sociedade, constituiu um fator determinante para a continuidade do projeto. Além disso, o fato da bacia fornecer água para mais de $60 \%$ da população garante o interesse constante na manutenção dos serviços hídricos em longo prazo e, consequentemente, garante a sustentação do esquema de PSA.

\section{CONCLUSÕES}

Em âmbito nacional e distrital há políticas públicas que permitem o desenvolvimento de programas de incentivos financeiros e econômicos para promover ações de mitigação e adaptação à mudança do clima. Fazendo, portanto, da atual crise o momento oportuno para por em prática tais políticas e ter como foco o aumento e regulação da vazão, principalmente devido ao fato de que os atuais programas de pagamento por serviços ambientais aplicados a recursos hídricos têm como foco principal a redução da sedimentação.

A crise hídrica no Distrito Federal é um sintoma tanto das mudanças climáticas locais quanto globais. Dessa forma, uma maneira de adequar o planejamento hídrico a essas mudanças é a implantação do uso do mecanismo de pagamento por 
serviços ambientais como ação de mitigação visto que o PSA é uma ferramenta de gestão essencial para o provimento e, principalmente, para a manutenção dos serviços hidrológicos.

O cálculo do pagamento por meio do excedente do consumidor não geraria ônus a Companhia de abastecimento de água do DF e beneficiaria os produtores de forma compensatória ao seu custo de oportunidade - no caso de recuperação de áreas - e nos custos de gerados pelas medidas de conservação do uso do solo.

Além disso, a arquitetura proposta integra os agricultores e os usuários a jusante da barragem do Descoberto. Ressaltase a não dependência de fundos de financiamento o que possibilita uma maior aceitação dos agricultores e, portanto, de aderência ao programa, visto a continuidade a longo prazo.

\section{REFERÊNCIAS}

ALÍPAZ, S. M. F. Quantificação e valoração econômica dos serviços ambientais redutores de sedimentação na bacia do Ribeirão Pipiripau. 2010. 101f. Dissertação (Mestrado em Ciências Florestais - Faculdade de Tecnologia, Universidade de Brasília, Brasília, 2010.

AZEVEDO, H. A. M. A.; BARBOSA, R. P. Gestão de recursos hídricos no Distrito Federal: uma análise da gestão dos Comitês de Bacias Hidrográficas. Ateliê Geográfico, Goiânia, v. 5, n. 1, p. 162-182, 2011. DOI: https://dx.doi.org/10.5216/ag.v5i1.13830

BALBINOT, R.; OLIVEIRA, N. K.; VANZETTO, S. C.; PEDROSO, K.; VALERIO, Á. F. O papel da floresta no ciclo hidrológico em bacias hidrográficas. Ambiência, Guarapuava, v. 4, n. 1, p. 131-149, 2009.

BOAVENTURA, J. M. G.; FISCHMANN, A. A. Um método para cenários empregando stakeholder analysis: um estudo no setor de automação comercial. Revista de Administração, v. 42, n. 2, p. 141-154, 2007. DOI: https://doi.org/10.1590/S0080-21072007000200003

BÖSCH, M.; ELSASSER, P.; WUNDER, S. Why do payments for watershed services emerge? A cross-country analysis of adoption contexts. World Development, Oxford, v. 119, p. 111-119, 2019. DOI: https://dx.doi.org/10.1016/j.worlddev.2019.03.010

BRASIL. Lei Federal $n^{0}$ 9.433/1997. Institui a Política Nacional de Recursos Hídricos, cria o Sistema Nacional de Gerenciamento de Recursos Hídricos, regulamenta o inciso XIX do art. 21 da Constituição Federal, e altera o art. $1^{\circ}$ da Lei $\mathrm{n}^{\circ}$ 8.001, de 13 de março de 1990, que modificou a Lei $\mathrm{n}^{\circ} 7.990$, de 28 de dezembro de 1989 Brasília, 1997.

Lei Federal $n^{\circ} 12.114 / 2009$. Cria o Fundo Nacional sobre Mudança do Clima, altera os arts. $6^{\circ}$ e 50 da Lei no 9.478, de 6 de agosto de 1997, e dá outras providências. Brasília, 2009a.

Lei Federal $\mathrm{n}^{\circ}$ 12.187/2009. Institui a Política Nacional sobre Mudança do Clima - PNMC e dá outras providências. Brasília, 2009b.

.Lei Federal $\mathrm{n}^{\mathrm{o}}$ 12.651/2012. Dispõe sobre a proteção da vegetação nativa; altera as Leis $n^{\text {os }} 6.938$, de 31 de agosto de 1981, 9.393, de 19 de dezembro de 1996, e 11.428, de 22 de dezembro de 2006; revoga as Leis $\mathrm{n}^{\text {os }} 4.771$, de 15 de setembro de 1965 , e 7.754 , de 14 de abril de 1989, e a Medida Provisória $n^{\circ}$ 2.166-67, de 24 de agosto de 2001; e dá outras providências. Brasília, 2012.

BRAUMAN, K. A.; DAILY, G. C.; DUARTE, T. K.; MOONEY, H. A. The nature and value of ecosystem services: an overview highlighting hydrologic services: An Overview Highlighting Hydrologic Services. Annual Review of Environment and Resources, Palo Alto, v. 32, p. 67-98, 2007. DOI: https://dx.doi.org/10.1146/annurev.energy.32.031306.102 758

BUENO, P. H. O. Desenvolvimento de procedimento para identificação de áreas prioritárias para o manejo das águas pluviais: aplicação para o caso da bacia do Alto Descoberto-DF/GO. 2016. 115f. Dissertação (Mestrado) - Universidade de Brasília. Faculdade de Tecnologia. Departamento de Engenharia Civil e Ambiental. 2016

CAMPANHÃO, L. M. B.; RANIERI, V. E. L. Guideline framework for effective targeting of payments for watershed services. Forest Policy and Economics, Amsterdam, v. 104, p. 93-109, 2019. DOI: https://dx.doi.org/10.1016/j.forpol.2019.04.002

CODEPLAN COMPANHIA DE PLANEJAMENTO DO DISTRITO FEDERAL. Pesquisa Distrital por Amostra de Domicílios. Disponível por meio de $<$ http://www.codeplan.df.gov.br/component/content/articl e/261-pesquisas-socioeconomicas/294-pdad-2013.html>. Acessado em 20 de abril de 2017.

DISTRITO FEDERAL. Lei $\mathrm{N}^{\mathrm{o}} 5.955$, de 02 de agosto de 2017. Institui a Política Distrital de Pagamentos por Serviços Ambientais e o Programa Distrital de Pagamento por Serviços Ambientais. Brasília, 2017.

FARLEY, J.; COSTANZA, R. Payments for ecosystem services: From local to global. Ecological Economics, Amsterdam, v. 69, n. 11, p. 2060-2068, 2010. DOI: https://dx.doi.org/10.1016/j.ecolecon.2010.06.010

FERREIRA, P.; VAN SOESBERGEN, A.; MULLIGAN, M.; FREITAS, M.; VALE, M. M. Can forests buffer negative impacts of land-use and climate changes on water ecosystem services? The case of a Brazilian megalopolis. Science of The Total Environment, Amsterdam, v. 685, p. 248-258, 2019. DOI: https://dx.doi.org/10.1016/j.scitotenv.2019.05.065

FLETCHER, T. D.; ANDRIEU, H.; HAMEL, P. Understanding, management and modelling of urban hydrology and its consequences for receiving waters: A state of the art. Advances in Water Resources, Southampton, v. 51, p. 261-279, 2013. DOI: https://dx.doi.org/10.1016/j.advwatres.2012.09.001

FLORES, R. K.; MISOCZKY, M. C. Dos Antagonismos na Apropriação Capitalista da Água à sua Concepção como Bem Comum. Organizações \& Sociedade, Salvador, v. 22, n. 73, p. 237-250, 2015. DOI: http://dx.doi.org/10.1590/1984-9230733

FONSECA, F. O. Olhares sobre o Lago Paranoá. 1. ed. Brasília: Secretaria de Meio Ambiente e dos Recursos Hídricos, 2001. $425 \mathrm{p}$

GJORUP, A. F.; FIDALGO, E. C. C.; PRADO, R. B.; SCHULER, A. E. Análise de procedimentos para seleção de áreas prioritárias em programas de pagamento por serviços ambientais hídricos. Revista Ambiente \& Água, Taubaté, v. 11, n. 1, p. 225, 2016. DOI: https://dx.doi.org/10.4136/ambi-agua. 1782 
GDF GOVERNO DO DISTRITO FEDERAL. Plano Integrado de Enfrentamento da Crise Hídrica. Disponível por meio de <http:// http://www.mpdft.mp.br/portal/pdf/eventos/crisehidrica/P LANO-INTEGRADO-DE-ENFRENTAMENTO-CRISEHIDRICA_21-2-2017.pdf $>$. Acessado em 20 de maio de 2017.

HUPFFER, H. M.; WEYERMULLER, A. R.; WACLAWOVSKY, W. G. Uma análise sistêmica do princípio do protetor-recebedor na institucionalização de programas de compensação por serviços ambientais. Ambiente \& Sociedade, São Paulo, v. 14, n. $1, \mathrm{p} . \quad 95-114, \quad 2011$ DOI: https://dx.doi.org/10.1590/s1414753x2011000100006

HONDA, E. A.; DURIGAN, G. A restauração de ecossistemas e a produção de água. Hoehnea, São Paulo, v. 44, n. 3, p. 315-327, 2017. DOI: http://dx.doi.org/10.1590/2236-8906-82/2016

IPCC INTERGOVERNMENTAL PANEL ON CLIMATE C $\bar{H} A N G E$. Climate Change 2013: Fifth Assessment Report. Genebra: IPCC, 2013.

JACKSON, S.; FINN, M.; SCHEEPERS, K. The use of replacement cost method to assess and manage the impacts of water resource development on Australian indigenous customary economies. Journal of Environmental Management, London, v. 135, p. 100-109, 2014. DOI: https://dx.doi.org/10.1016/j.jenvman.2014.01.018

JARDIM, M. H.; BURSZTYN, M. A. Pagamento por serviços ambientais na gestão de recursos hídricos: o caso de Extrema (MG). Engenharia Sanitária e Ambiental, Rio de Janeiro, v. 20, n. 3, p. 353-360, 2015. DOI: https://dx.doi.org/10.1590/s141341522015020000106299

JYRKAM, M. I.; SYKES, J. F. The impact of climate change on spatially varying groundwater recharge in the grand river watershed (Ontario). Journal of Hydrology, Amsterdam, v. 338, p. 237-250, 2007. DOI: https://dx.doi.org/10.1016/j.jhydrol.2007.02.036

KOSOY, N.; CORBERA, E. Payments for ecosystem services as commodity fetishism. Ecological Economics, Amsterdam, v. 69, n. 6, p. 1228-1236, 2010. DOI: https://dx.doi.org/10.1016/j.ecolecon.2009.11.002

MARENGO, J. A.; NOBRE, C. A.; SELUCHI, M. E.; CUARTAS, A.; ALVES, L. M.; MENDIONDO, E. M.; OBREGÓN, G.; SAMPAIO, G. A seca e a crise hídrica de 2014-2015 em São Paulo. Revista USP, São Paulo, n. 106, p. 31-44, 2015. DOI: http://dx.doi.org/10.11606/issn.2316-9036.v0i106p31-44

MOTTA, R. S. Manual para Valoração Econômica de Recursos Ambientais. Rio de Janeiro, IPEA/MMA/PNUD/CNPq, 1997. 254p.

MURADIAN, R.; CORBERA, E.; PASCUAL, U.; KOSOY, N.; MAY, P. H. Reconciling theory and practice: An alternative conceptual framework for understanding payments for environmental services. Ecological Economics, Amsterdam, v. 69, n. 6, p. 1202-1208, 2010. DOI: https://dx.doi.org/10.1016/j.ecolecon.2009.11.006

NEITSCH, S.; ARNOLD, J. G.; KINIRY, J. R.; SRINIVASAN, R.; WILLIAMS, J. Soil and Water Assessment Tool: Theoretical Documentation: Version 2005. Temple, Texas, 2005. 494 p.
NOTARO, S.; PALETTO, A. The economic valuation of natural hazards in mountain forests: An approach based on the replacement cost method. Journal of Forest Economics, v. 18, n. 4, p. 318-328, 2012. DOI: https://dx.doi.org/10.1016/j.jfe.2012.06.002

NUNES, J. F. O modelo LUCIS e o planejamento territorial da bacia do Alto Rio Descoberto. 2014. 123 f. Dissertação de Mestrado - Universidade de Brasília, Brasília, 2014.

OUVERNEY, I. R.; MOTTA, R. S. D.; ORTIZ, R. A.; COELHO, P. S. Condicionantes da disposição de participar e aceitar pagamentos por serviços ambientais: um estudo de caso no brasil. Revista de Economia Contemporânea, Rio de Janeiro, v. 21, n. 3, p. 2017. DOI: http://dx.doi.org/10.1590/198055272134

PEARCE, D. W. Economic Value and the Natural World. The MIT Press, Cambridge, Massachusetts, 1993. 129 p.

PORRAS, I.; GRIEG-GRAN, M.; NEVES, N. All That Glitters: A Review of Payments for Watershed Services. London: International Institute for Environment and Development (IIED), 2008. 129 p.

RICKERT, B.; VAN DEN BERG, H.; BEKURE, K.; GIRMA, S.; DE RODA HUSMAN, A. M. Including aspects of climate change into water safety planning: Literature review of global experience and case studies from Ethiopian urban supplies. International Journal of Hygiene and Environmental Health, Jena, v. 222, n. 5, p. 744-755, 2019

DOI: https://dx.doi.org/10.1016/j.ijheh.2019.05.007

SANDERSON, E. W.; JAITEH, M.; LEVY, M. A.; REDFORD, K. H.; WANNEBO, A. V.; WOOLMER, G. The human footprint and the last of the wild. BioScience, Oxford, v. 52, n. 10, p. 891-904, 2002. DOI: https://dx.doi.org/10.1641/00063568(2002)052[0891:thfatl]2.0.co;2

SCHOMERS, S.; MATZDORF, B. Payments for ecosystem services: A review and comparison of developing and industrialized countries. Ecosystem Services, v. 6, p. 1630, 2013.2 DOI: https://dx.doi.org/10.1016/j.ecoser.2013.01.002

SEGETH. Limite do DF. Distrito Federal, 2017. Disponível em: $\quad$ https://www.geoportal.segeth.df.gov.br/mapa/\#. Acesso em: 13 jan. 2018.

SIEG_SISTEMA ESTADUAL DE GEOINFORMAÇÃO DE GÖIÁS. Disponível em: http://www.sieg.go.gov.br/. Acesso em: 07 nov. 2018.

SONE, J. S.; GESUALDO, G. C.; ZAMBONI, P. A. P.; VIEIRA, N. O. M.; MATTOS, T. S.; CARVALHO, G. A.; RODRIGUES, D. B. B.; ALVES SOBRINHO, T.; OLIVEIRA, P. T. S. Water provisioning improvement through payment for ecosystem services. Science of The Total Environment, Amsterdam, v. 655, p. 1197-1206, 2019.

DOI: https://dx.doi.org/10.1016/j.scitotenv.2018.11.319

VAN HECKEN, G.; BASTIAENSEN, J. Payments for ecosystem services: justified or not? A political view. Environmental Science \& Policy, Exeter, v. 13, n. 8, p. 785-792, 2010.

DOI: https://dx.doi.org/10.1016/j.envsci.2010.09.006

VASCONCELOS, S. M. S. Avaliação da recarga subterrânea através da variação do nível potenciométrico no aquífero Dunas/Paleodunas, Fortaleza, Ceará. Revista Brasileira 
de Recursos Hidrícos, Porto Alegre, v. 10, n. 2, p. 49-57, 2005.DOI: https://dx.doi.org/10.21168/rbrh.v10n2.p4957

WUNDER, S. Revisiting the concept of payments for environmental services. Ecological Economics, Amsterdam, v. 117, p. 234-243, 2015. DOI: https://dx.doi.org/10.1016/j.ecolecon.2014.08.016

WUNDER, S. Payments for environmental services and the poor: concepts and preliminary evidence. Environment and Development Economics, Cambridge, v. 13, n. 3, p. 279-297, 2008

DOI: https://dx.doi.org/10.1017/S1355770X08004282

WUNDER, S. Payments for environmental services: some nuts and bolts. Bogor: CIFOR Occasional paper 42. Center for International Forestry Research, 2005.

WÜNSCHER, T.; ENGEL, S.; WUNDER, S. Spatial targeting of payments for environmental services: a tool for boosting conservation benefits. Ecological Economics, Amsterdam, v. 65, n. 4, p. 822-833, 2008. DOI: https://dx.doi.org/10.1016/j.ecolecon.2007.11.014

YANG, X.; SUN, W.; LI, P.; MU, X.; GAO, P.; ZHAO, G. Integrating agricultural land, water yield and soil conservation trade-offs into spatial land use planning. Ecological Indicators, v. 104, p. 219-228, 2019. DOI: https://dx.doi.org/10.1016/j.ecolind.2019.04.082 